\title{
Ornitologické pozorovania
}

\section{Ornithological observations}

\begin{abstract}
Ďalšou čast'ou Ornitologických pozorovaní pokračujeme v publikovaní avifaunistických materiálov z územia Slovenska. Údaje sú spracované rovnako ako $\mathrm{v}$ predchádzajúcich častiach, ktoré vyšli v časopise Tichodroma. Aj v tejto časti Ornitologických pozorovaní uverejňujeme niektoré staršie údaje $\mathrm{z}$ rôznych rukopisných archívnych materiálov. Ide o údaje z lokalít, ktoré zanikli, alebo zmenili svoj pôvodný charakter.
\end{abstract}

- Accipiter gentilis: 30. 4. 1963 Baka (8170) „Ostrov orliakov morských“ obsadené hniezdo, jastrab vyletel z hniezda - A. Stollmann.

- Accipiter nisus: 22. 4. 2020 Bratislava - Petržalka (7868) „Soví les“ čerstvo postavené hniezdo na topoli asi $18 \mathrm{~m}$ vysoko v mladšom topol'ovom lužnom lese, pár sa zdržuje na hniezde. Ďalší priebeh hniezdenia: 9. 5. samica pevne sedí na násade, 6. 6. samica stojí pri mlád'atách, 4. 7. hniezdo bolo predované (mlád’atá v hniezde nie sú) - P. Rác.

- Acrocephalus schoenobaenus: nálezy hniezd na „Čičovskom mítvom ramene“ pri Čičove (8272): 25. a 27. 6. 1993 - $2 \times 4$ ks násady, 11. a 15. 6 . 1994-2× 6 ks násady, 18. 6. 1999-6 ks násada, 15. 6. $2001-4 \mathrm{ks}$ násada, 18. a 21. 6. $2003-2 \times 5$ ks násady. Všetko P. Rác.

- Acrocephalus scirpaceus: nálezy hniezd a výskyt spievajúcich samcov (teritoriálne vtáky) v inundačnom pásme Dunaja pred výstavbou vodného diela (v rokoch 1986 až 1992): Vojka nad Dunajom (8070) ostrov „Öreg nádas“ (rkm 1837) 11. 7. 1987 v trstinovom záraste na jazierku hniezda s 3 pull. a 1 hluchým vajcom, hniezdo s kukučkou a 2 vyvedené hniezda, 28. 5. 1988 spieva niekol'ko ex. a 10 . 7. 1988 tam 2 vyvedené hniezda, 23. 6. 1990 a 2.6 . 1991 spieva niekol'ko ex., 6. 5.1992 spieva 1 ex.; Horný Bar - Šul'any (8070) jazierko „Főványköz“ na dunajskom ostrove (rkm 1831) 12. 7. $1986 \mathrm{v}$ trstinovom záraste spieva 1 ex., 14. 7. 1987 tam hniezda so 4 ks násadou, 4 pull. a 3 vyvedené hniezda, 19. 4. 1990 spieva 1 ex.; Bodíky (8070) pobrežný zárast trste (o celkovej dížke $400 \mathrm{~m}$ ) pri ostrove „Akácos“(rkm 1828) 3. 7. 1988 hniezda s $2 \times 4$ ks násadami, 3 ks násadou, 2 ks násadou (slabo nasadnutou), 3 pull., hniezdo s vajcom kukučky a 4 prázdne hniezda (s vyvedenými a zničenými násadami); Bodíky (8170) pobrežný zárast trste pri ramene „Forás“ (rkm 1825,4) 30. 6. 1990 hniezdo so 4 ks násadou a hniezdo s 2 pull. a 1 hluchým vajcom; Baka (8170) ostrov „Gólyás“ (rkm 1824,5) 29.6.1990 v pobrežnej trstine spieva niekol'ko ex.; Baka (8170) „Ostrov orliakov morských“ (rkm 1823) 12.7. $1988 \mathrm{v}$ pobrežnej trstine hniezdo so 4 ks násadou a v blízkych pobrežných trstinách d'alšie 2 vyvedené hniezda, 26. 4.1989 v blízkych pobrežných trstinách spieva niekol'ko ex.; Baka (8171) ostrov „Kalap“(rkm 1821,5) 15. 7. 1987 v trstinovom záraste na jazierku spievajú 2 ex., 6. 7. 1988 tam hniezda so 4 ks násadou, 4 pull., s uhynutými pull. a 2 prázdne hniezda (so zanechaným vajcom a vyvedené hniezdo); Baka (8171) ostrov „Vajas“ (rkm 1821 - 1822) 13. 7.1988 v pobrežnej trstine hniezdo so 4 pull., 26. 4. $1989 \mathrm{v}$ trstinovom záraste na jazierku spieva niekol'ko ex.; Gabčíkovo (8171) trstinové porasty na ostrove „Isztragov“ (rkm 1817) 5. 7. 1986 spievajú 3 ex., 29. 4.1988 spieva 1 ex., 22. 4. 1989 spieva niekol'ko ex. a 9. 6. 1989 tam hniezdo s vajcom kukučky, 24 . 4. 1990 spieva niekol'ko ex. a 2. 6. 1990 tam rozostavané hniezdo (neskôr nekontrolované), 12.4. 1991 a 14. 4. 1992 spieva 1 ex., 22. 5. $1992 \mathrm{v}$ pril'ahlých pobrežných trstinách pri hlavnom toku Dunaja spieva niekol'ko ex.; Gabčíkovo (8171) ostrov „Foki“ (rkm 1815) 10.6. 1989, 5. 5. 1991 a 22. 5. 1992 v pobrežnej trstine spievajú 1 - 2 ex.; Gabčíkovo (8171) ostrov „Ercséd“ (rkm 1812 - 1816) 22.6. 1986 a 19. $7.1987 \mathrm{v}$ trstinových zárastoch na jazierkach spievajú $1-2$ ex., 
11. 6. 1989 a 22. 7.1990 tam 2 prázdne hniezda; Kl'účovec (8272) ostrov naproti obci (rkm 1802) 17. $5.1986 \mathrm{v}$ trstinovom záraste na jazierku spieva 1 ex., 27. 6. 1987 tam hniezdo s kukučkou. Všetko - P. Rác.

- Anas querquedula: 4. 5. 1967 Vel'ké Blahovo (7971) na poloprázdnom rybníku (=močiari) hniezdo s 11 ks násadou-leg. F. Matoušek (coll. SNM-PM Bratislava); hniezdne obdobie 1981 „Vlhká lúka“ v medzihrádzovom priestore Vážskeho Dunaja nad Komárnom (8274) výskyt v počte až do 40 ex., predpokladané hniezdenie - M. Bohuš.

- Ardea purpurea: 12.5. 1937 mítve rameno „Rákászó“ pri Gabčíkove (8171) pozorovaných 10 - 12 exemplárov - F. Matoušek; 27. 4. 1962 mŕtve rameno „Dékány“ pri Gabčíkove (8171) v trstine v blízkosti hrádze hniezdi asi 8 - 10 párov, 14. 6. 1963 ned’aleko je rozostavané stavidlo a odvodňovací kanál, voda na lokalite klesla asi o $1 / 2 \mathrm{~m}$, volavky purpurové tam už nehniezdia - F. Matoušek \& B. Matoušek.

- Asio otus: 20. 5. 1974 Bratislava - Petržalka (7868) 4 ks násada v opustenom holubníku v bývalom pol'ovníckom stredisku Ovsište na okraji lužného lesa. V nasledujúcom roku 16. 5. 1975 bola v holubníku znova 3 ks násada - P. Rác.

- Botaurus stellaris: rybníky pri Vel'kom Blahove (7971) 4. až 6. 5.1967 ozýva sa 1 samec - F. Matoušek, 25. 4. 1968 ozýva sa 1 samec (večer) - porybný P. Podhradský, 21. 7. 1989 ozýva sa 1 samec-M. Deraj, 10. 6. 2004 ozývajú sa 2 samci - J. Lengyel, 26. 4. 2006 ozýva sa $1 \mathrm{samec}$ - R. Kvetko; rybníky pri Dolnom Štále (8072) 3. 5. 1997 ozýva sa 1 samecM. Privrel, 12. 5. 2006 ozýva sa 1 samec-M. Kúdela, 9. 6. 2015 ozýva sa 1 samec - R. Kvetko; rybníky pri Bohelove (8072) 26. 5. 2004 ozýva sa 1 samec - J. Lengyel; Vrbová nad Váhom (8174) „Listové jazero“ 24. 5. 1961 ozývajú sa 2 samce - A. Stollmann, 17. 6. 1964 ozýva sa 1 samec - A. Randík.

- Ciconia nigra: 17. 1. 2018 Kútniky (8071) pri zimnom sčítaní vodného vtáctva nájdené hniezdo v pol'nom topolovom stromoradí pri kanáli južne od obce. V hniezdnom období 2018 a 2019 hniezdo nebolo kontrolované, 22. 7. 2020 tam bociany čierne nehniezdili (pod hniezdom boli zbytky trusu, pri hniezde sa musel bocian čierny zdržovat') - S. Pačenovský. Corrigenda: v Ornitologických pozorovaniach (Rác 2019) došlo k chybe v lokalizácii: namiesto Kolárovo (8174) l’avobrežný brehový porast Vážskeho Dunaja pod mestom má byt' správne: Kolárovo (8174) pravobrežný brehový porast Vážskeho Dunaja pod mestom: 2005 hniezdo s 3 mlád'atami - M. Galovič.
- Circus aeruginosus: 21. 5. 1956 pár kaní močiarnych dokončuje stavbu hniezda (2.6. hniezdo prázdne), 20. 6. 1963 hniezdi 1 pár všetko na mítvom ramene „Rákászó“ pri Gabčíkove (8171) - F. Matoušek; 28. 6. 2001 nález hniezda so 7 mlád'atami ( 5 mlád’at bolo krúžkovaných 2 najmladšie mlád’atá sa ešte nedali krúžkovat') v trst'ovom záraste odvodňovacieho kanála medzi obcou Okoličná na Ostrove a osadou Štúrová (8173), neskôr hniezdo už nebolo sledované - V. Slobodník \& R. Slobodník.

- Coloeus monedula: hniezdenie na „Močianskom ostrove“ pri Moči (8276) v heterogénnej kolónii Ardea cinerea, Nycticorax nycticorax, Phalacrocorax carbo a Corvus frugilegus: 12.4. $1980 \mathrm{z}$ ostrova sa ozývajú kavky, 14. 5. 1984 hniezdenie (bez počtu) A. Sághy; 22. 4. 1985 hniezdi asi 5 párov - S. Faragó; 11. 5.1986 nájdené 2 hniezda v dutinách stromov s 5 ks násadou a s 5 pull., 19. 4. 1987 hniezdenie (bez počtu) - M. Bohuš; 18. 5. 1988 hniezdi asi 5 párov - A. Sághy; 14. 5. a 7. 6. 1990 hniezdenie (bez počtu) - A. Sághy \& J. Chavko; 28. 5 . 2006 hniezdi asi 5 párov - A. Bagdi.

- Columba palumbus: zimovanie v mestskej aglomerácii Bratislavy (7868): 15. 1. 2002 Štefániková ul. 1 ex. (prvý registrovaný zimný výskyt v mestskej aglomerácii) - P. Rác. V nasledujúcich rokoch sa počty zimujúcich holubov hrivnákov v mestskej aglomerácii postupne zvyšujú: 30. 1. 2010 Pankúchova ul. v Petržalke 8 ex. - K. Balažovičová, 23. 12. 2010 Spojná ul. 7 ex. - P. Rác, d’alšie výskyty uvádza databáza aves. vtaky.sk, a na Ondrejskom cintoríne vzniká hromadné nocovisko zimujúcich vtákov: 13. 12. 2017 už 462 ex. - Pačenovský (2018), 30. 1. 2019 a 25. 1. 2020 najmenej 300 ex. - P. Rác. Zimujúce holuby hrivnáky v uliciach Bratislavy boli často pozorované pri oberaní plodov brestovca (Celthis).

- Coracias garrulus: 4. 9. 1976 Lehnice (7970) 1 ex. - P. Rác, 5. 9. 1952 Zlatná na Ostrove (8273) 2 ex. A. Stollmann, 10. 9. 1972 Zlatná na Ostrove-Vel'ký Lél (8273) 1 ex.-P. Binder, 5. 9., 8. 9. a 14. 9. 1984 Komárno-Nová Osada (8274) vždy 1 ex. na hrádzi-M. Deraj.

- Cygnus olor: 28. 10. 1989 Čičov (8272) 197 ex. na novovybudovaných rybníkoch - P. Rác.

- Erithacus rubecula: 27. 4. 1930 Šamorín - Čilistov (7969) hniezdo so 6 ks násadou v brehu vyschnutého ramena - L. Csiba, 1. 6. 1961 Bodíky (8070) hniezdo v polodutine vŕby $50 \mathrm{~cm}$ vysoko $\mathrm{s}$ vyplavenou násadou a druhé hniezdo v brehu ramena s čerstvou $6 \mathrm{ks}$ násadou - B. Matoušek, 24. 4. 1981 Čičov (8272) hniezdo so 7 ks násadou na zemi, 2. 5. 1987 Gabčíkovo 
(8171) hniezdo so 7 ks násadou na zemi - P. Rác, máj 1997 Bodíky (8170) hniezdo vol’ne postavené v spleti kríkov a popínavých rastlín nízko nad zemou a druhé hniezdo postavené v spleti výmladkov pri kmeni brestu - B. Roková.

- Falco tinnunculus: 18. a 19.4. 1956 Hubice (7870) v parku pri kaštieli pár zaletuje do dutiny dubu; 19. 4. 1956 Kvetoslavov (7970) podl'a informácie (od miestneho lesníka) v borovicovom lesíku nad obcou je kolónia niekol'kých párov, vtáky tam hniezdia v hniezdach vrán - všetko F. Balát; 5. 4. 1967 Gabčíkovo (8171) hniezdo s čiastočnou násadou 3 vajcia v kotline hlavatej vŕby asi 2 m vysoko na ostrove „Isztragov“ F. Matoušek \& A. Stollmann; 6. 4. 1972 hniezdiaci pár v kolónii volaviek popolavých a havranov čiernych na dunajskom ostrove v katastri obce Mužla (8277) P. Binder.

- Haliaeetus albicilla: 2. 1. 2020 Vrbová nad Váhom (8174) nájdené hniezdo (staršia stavba) čerstvo nadstavené v topol'ovom poraste pri „Listovom jazere“. Ďalšie sledovanie tejto lokality v roku 2020: 25. 2. pár orliakov vyletel z hniezda (jeden z páru bol vyfarbený adultný vták, druhý bol jedinec ešte nie s čiste bielym chvostom), 26. 4. orliaky na hniezde nepozorované, 2. 6. pár orliakov morských nocuje v poraste pri hniezde, 11. 9. adult. orliak sedí v poraste pri hniezde - všetko J. Lengyel. Podl'a informácie A. Zubera (dobrovol'ná stráž ochrany prírody) hniezdo bolo postavené v roku 2015 a orliaky hniezdo každoročne obsadzovali (bližšie údaje si nezaznamenal).

- Hippolais icterina: 21. 7. 1953 Bratislava-Podunajské Biskupice (7969) krúžkované 3 pull. v hniezde-F. Balát.

- Charadrius dubius: 23. 6. 1950 Kamenica nad Hronom (8178) na štrkových laviciach na sútoku Hrona s Dunajom hniezdi niekol'ko párov, jedno hniezdo so 4 ks násadou nájdené - M. Bališ \& J. Brtek ml.; 9. 6.1960 Kalinkovo (7969) 3 hniezdiace páry na štrkovom brehu „Ostrova kormoránov“ - J. Ponec; 2. 6. 1979 Dobrohošt' (8070) 2 hniezdiace páry na štrkovom brehu Dunaja (1 mlád’a chytené); 24. 5. 1981 Kl'účovec (8272) 3 páry vyhlbujú hniezda na štrkovej lavici Dunaja; 11. 6. 1988 Kližská Nemá (8272) 2 hniezdiace páry na štrkovej navážke pri hrádzi a d’alšie 2 hniezdiace páry na štrkovej lavici Dunaja; 18. 6. 1990 Kl'účovec (8272) 2 hniezdiace páry na štrkovej navážke pri Dunaji (1 mlád’a pozorované); 19. 6. 1990 \& 1. 6. 1991 \& 30. 5. 1992 Medved’ov (8271) vždy 2 hniezdiace páry na štrkovej navážke pri Dunaji (1.6. 1991 - 1 mlád’a pozorované) - všetko P. Rác.
- Ixobrychus minutus: 17. 5. 1952 Gabčíkovo (8171) mítve rameno „Nagyerdo““: nájdené 3 hniezda, v jednom bola čiastočná násada 4 vajcia (coll. SNM-PM Bratislava), d'alšie 2 hniezda boli ešte bez násady; 6. 5. 1956 Čičov (8272) „Čičovské mŕtve rameno“ pozorovaných asi 8 ex. (len na časti mŕtveho ramena) - všetko F. Matoušek.

- Locustella fluviatilis: 22. 5. 1943 Kalinkovo (7969) „Ostrov kormoránov“ 1 ex. v coll. SNM-PM Bratislava (lokalizovaný ako Podunajské Biskupice) - leg. O. Ferianc, 25. 5. 1962 Bratislava - Podunajské Biskupice (7868, 7968) ostrov „Kopáć“ 1 ex. v coll. SNM-PM Bratislava - leg. B. Matoušek.

- Locustella luscinioides: 17. 4. 1967 Gabčíkovo (8171) 1 ex. spieva na mŕtvom ramene „Rákászó“ - F. Matoušek.

- Luscinia megarhynchos: 20. 6. 1950 Šamorín (7969) hniezdo s čerstvo vyliahnutými pull. (počet nezistený) v lužnom lese - M. Bališ, 18. 5. 1986 Bratislava Podunajské Biskupice (7868, 7968) ostrov „Kopáč“ hniezdo s 5 ks násadou v lužnom lese - P. Rác. Historický nález hniezda: 22. 5. 1902 Bratislava-Petržalka (7868) miestna čast' „Starý háj“ hniezdo s 5 ks násadou - leg. et coll. G. Ertl (Ertl Gusztáv tojásgyüjteményének jegyzéke. Manuskript depon in Magyar Természettudományi Múzeum, Budapest).

- Phalacrocorax carbo: 21. 4. 1943 Kalinkovo (7969) „Ostrov kormoránov“ 3 ks násada (leg. L. Máté) v coll. L. Povázsayho v MTM Budapešt'. Corrigenda: Povázsay (1986) lokalizoval túto násadu lokalitou Dunacsún (protil'ahlá obec naproti „Ostrovu kormoránov“, dnes Bratislava-Čunovo) s chybným datovaním (21. 6. 1944) a takto to prebrali aj Fuisz et al. (2017). 20. 4. 1943 Kalinkovo (7969) „Ostrov kormoránov“ násada 1 vajce (leg. L. Máté) v coll. L. Nemereho v Budapešti (súkromná coll.). Corrigenda: táto násada je v coll. L. Nemereho tiež lokalizovaná lokalitou Dunacsún s chybným datovaním (20. 5. 1943) a s chybným autorom zberu (N. Homonnay) a takto to prebral aj Haraszthy (2015). V roku 1943 (20. a 21. apríla) zbieral násady kormoránov na „Ostrove kormoránov“ Máté (1943)! Z tohto zberu (všetko leg. L. Máté) pochádza aj 2 ks násada (20. 4. 1943) v coll. L. Povázsayho st. v Békéscsabe (súkromná coll., ktorá sa však nezachovala-pozri Haraszthy 2015) a 1 ks násada (21. 4. 1943) v coll. L. Erdősa v SNM-PM Bratislava (lokalizovaná ako Bratislava, miestna čast' Čunovo - pozri Matoušek 2009). 15. 4. 1950 Kalinkovo (7969) „Ostrov Kormoránov“ $2 \mathrm{ks}$ a $2 \times 3 \mathrm{ks}$ násady -1 leg. et coll. J. Ponec (dnes coll. SNM-PM Bratislava). 
- Podiceps cristatus: 4. a 5. 4. 1967 pozorovaný 1 pár na ostrove „Isztragov“ pri Gabčíkove (8171) - F. Matoušek.

- Remiz pendulinus: historické doklady v coll. Magyar Természettudományi Múzeum v Budapešti: 31. 7. 1891 -1 juv. ex., 3. 3. $1894-1$ adult. ex., 22. 7. $1895-6$ juv. ex. všetko z lokality Šamorín (7969), leg. K. Kunszt (kartotéka kožkového materiálu MTM v Budapešti). Doklady v roku 1956 zhoreli, zachovala sa len dokumentácia.

- Sylvia nisoria: nálezy hniezd v podunajských lužných lesoch a v pril'ahlom území: 22. 5. 1994 čiastočná násada 3 vajcia (neskôr zničená) a 6 ks násada, 2. 6. $1994-5$ ks násada, 23. 5. 1995 - 5 ks násada, 23. 5. 2001 - 5 ks násada Bratislava - Podunajské Biskupice (7868, 7968) ostrov „Kopáć“; 28. 5. 1979 - 5 ks násada Bratislava - Podunajské Biskupice (7969) „Pol'ovnícky les“; 1.6.1986 - 5 ks násada Hamuliakovo (7969); 22. 5. 2007 - 4 ks a $5 \mathrm{ks}$ násada Dobrohošt' (8070); 28. 5. 1988 čiastočná násada 4 vajcia (neskôr opustená), 29. 5. 1993 hniezdo s 2 pull. asi 2 dni starými, 24. 5. 2001 - 5 ks násada, 22. 5. 2002 čiastočná násada 1 vajce (doplnená na 4 ks násadu) a 6 ks násada, 25. 5. 2002 - 4 ks násada, 5 ks násada a hniezdo so 4 pull. asi 2 dni starými, 15. 5.2003 čiastočná násada 3 vajcia (doplnená na 5 ks násadu) a 5 ks násada, 23. 5. 2003 - $2 \times 5$ ks násady, 18. 5. 2004 čiastočná násada 1 vajce (doplnená na 5 ks násadu) a 6 ks násada, 19. 5. 2004 čiastočná násada 2 vajcia (doplnená na 5 ks násadu) a $2 \times 6$ ks násady, 25. 5.2006 čiastočná násada 2 vajcia (doplnená na 5 ks násadu) a $3 \times 5$ ks násady, 23. 5. 2007 - 2×5 ks násady všetko Vojka nad Dunajom (8070); 21. 5. 1992 - 5 ks násada, 23. 5. 2008 - 5 ks násada, 6. 6. 2009 - 5 ks násada Horný Bar - Šul'any (8070); 28. 5. $1994-2 \times$ 5 ks násady, 6 ks násada a hniezdo so 6 pull. asi 2 dni starými, 29. 5. 1994 hniezdo s 5 pull. asi 2 dni starými, 24. 5 . $1995-2 \times 5$ ks násady a hniezdo s 5 pull. asi 3 dni starými, 27. 5. $2001-2 \times 5$ ks násady, 16. 5. 2003 - 4 ks násada, 28. 5. 2004 - 5 ks násada, 15. 5. $2005-$ 5 ks násada všetko Bodíky (8070, 8170); 23. 5. 2005 -5 ks násada Baka (8171); 8. 6. 1991 hniezdo s 5 pull. asi 8 - 9 dní starými, 27. 5. 1994 - 7 ks násada a hniezdo s 3 pull. asi 9 - 10 dní starými, 28. 5. 2008 hniezdo s 5 pull. asi 8 dní starými Gabčíkovo (8171); 16. 5. 2002 -6 ks násada, 13. 5. 2006 čiastočná násada 2 vajcia (doplnená na 5 ks násadu) Klúčovec (8272); 7. 6. 1987 - 5 ks násada, 3. 6. 2000 hniezdo s 5 pull. pred vyletením Čičov (8274); 31. 5. 2003 - 4 ks násada Zlatná na Ostrove (8273),,Vel'kolélsky ostrov“. Všetko
- P. Rác. Historické doklady: 18. 5. 1898 Bratislava Petržalka (7868) „Sad Janka Král'a“ 5 ks násada - leg. et coll. G. Ertl (Ertl Gusztáv tojásgyűjteményének jegyzéke. Manuskript depon. in Magyar Természettudományi Múzeum, Budapest; doklad sa nezachoval); 4. 6. 1930 Šamorín (7969) 1 samec ulovený - leg. Z. Frankenberger pre coll. Slovenského vlastivedného múzea v Bratislave (doklad sa nezachoval, Prírastkový katalóg Vtáky v SNM-PM Bratislava).

\section{Literatúra}

Fuisz T. I., Pereszlényi Á., Vas Z., Haraszthy L., Dulai D., SAliga R. \& Simon G. 2017: Ifjabb Povázsay László tojásgyüjteménye a Magyar Természettudományi Múzeum Madárgyűjteményében. - Annales Mus. hist. -nat. hung. 109: 185-241.

Haraszthy L. 2015: Nemere Lajos tojásgyüjteménye. Pp.: 455-480. In: Haraszthy L. (ed.): Magyarországi tojásgyüjtemények katalógusai. Pro Vértes Nonprofit Zrt., Csákvár.

Haraszthy L. 2015: Idősebb Povázsay László tojásgyűjteménye. - Pp.: 529-578. In: Haraszthy L. (ed.): Magyarországi tojásgyűjtemények katalógusai. — Pro Vértes Nonprofit Zrt., Csákvár.

MAтоUŠEK B. 2009: László Erdős - ornitológ, oológ a zberatel.' 1. Čast'. - Acta Rer. Natur. Mus. Nat. Slov. 55: 38-82.

Máté L. 1943: Nagy kárókatona fészektelep a Csallóközben. - Aquila 50: 408.

PAČENOvskÝ S. 2018: Zimovanie stoviek holubov hrivnákov na Ondrejskom cintoríne v Bratislave. — Vtáky 13 (2): 9.

Povázsay L. 1986: A Povázsay- féle madártojás- gyűjtemény katalógusa. - Környezet- és Természetvédelmi Évkönyv 7: 117-155.

RÁc P. (ed.) 2019: Ornitologické pozorovania. — Tichodroma 31: 56-58.

Zostavil: Peter Rác

Received: 10. 1. 2021

Accepted: 11. 1. 2021

Online: 28. 2. 2021 